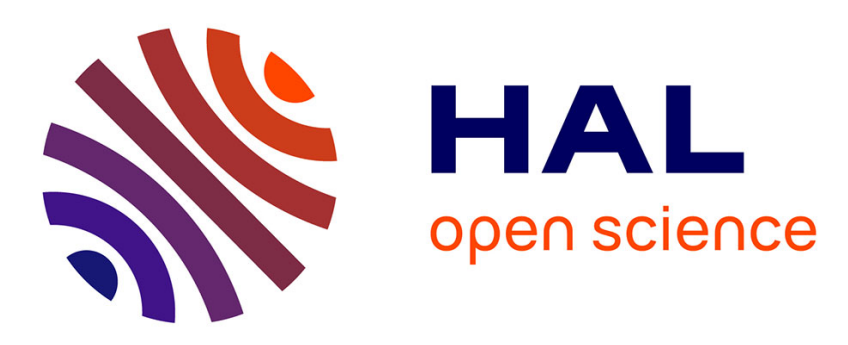

\title{
Transmission electron microscopical imaging of lateral implantation effects near mask edges in $\mathrm{B}+$-implanted $\mathrm{Si}$ wafers
}

\author{
E.F. Krimmel, H. Oppolzer, H. Runge
}

\section{- To cite this version:}

E.F. Krimmel, H. Oppolzer, H. Runge. Transmission electron microscopical imaging of lateral implantation effects near mask edges in B+-implanted Si wafers. Revue de Physique Appliquée, 1978, 13 (12), pp.791-795. 10.1051/rphysap:019780013012079100 . jpa-00244548

HAL Id: jpa-00244548

https://hal.science/jpa-00244548

Submitted on 1 Jan 1978

HAL is a multi-disciplinary open access archive for the deposit and dissemination of scientific research documents, whether they are published or not. The documents may come from teaching and research institutions in France or abroad, or from public or private research centers.
L'archive ouverte pluridisciplinaire HAL, est destinée au dépôt et à la diffusion de documents scientifiques de niveau recherche, publiés ou non, émanant des établissements d'enseignement et de recherche français ou étrangers, des laboratoires publics ou privés. 


\title{
DEFECTS AND CHARACTERIZATION I.
}

\section{TRANSMISSION ELECTRON MICROSCOPICAL IMAGING OF LATERAL IMPLANTATION EFFECTS NEAR MASK EDGES IN $B^{+}$-IMPLANTED Si WAFERS}

\author{
E. F. KRIMMEL, H. OPPOLZER and H. RUNGE
}

Forschungslaboratorien der Siemens AG, Muenchen, R.F.A.

\begin{abstract}
Résumé. - La microscopie électronique à transmission (TEM) d'échantillons à coupe transversale est utilisée pour illustrer la répartition des altérations par radiation aux contours des masques sur les structures en silicium à implantation $\mathrm{B}^{+}$. La répartition latérale de ces altérations est calculée pour des contours quelconques de masques. Les calculs théoriques et les résultats des expériences concordent et prouvent qu'il est absolument nécessaire de tenir compte de la répartition latérale lors du bombardement ionique des circuits à très grand degré d'intégration (VLSI).
\end{abstract}

\begin{abstract}
Transmission electron microscopy (TEM) of cross-sectional specimens is used to image the radiation damage distribution near mask edges in $\mathrm{B}^{+}$-implanted $\mathrm{Si}$ structures. The lateral spread of the radiation damage is calculated for arbitrarily shaped mask edges. Agreement between theoretical calculations and experimental results shows the need to take account of lateral spread in ion-implanted very-large-scale-integrated semiconductor devices (VLSI).
\end{abstract}

1. Introduction. - Because of advancing microminiaturization in very-large-scale-integrated semiconductor devices (VLSI), it has to be investigated if in addition to effects being caused e.g. by depletion layer width and finite slope of mask edge, also the lateral spread of radiation damage profiles and implantation profiles near mask edges due to ion scattering in the sample may set a limit to the maximum obtainable packing density.

The influence of lateral scattering on the ion and radiation damage distribution near infinitely high and infinitely steep mask edges was first investigated theoretically and experimentally in a fundamental work by Matsumura et al. [1, 2]. It was shown that the considerable lateral spread of the distribution of implants and damage should not be neglected, but no detailed information was given on practical cases of, for instance, chemically or ion etched masks with arbitrarily shaped edges, such as is necessary for device production.

Thus device-oriented mask edges were calculated [3] to determine the lateral spread of the ion distribution after implantation. Initial experiments in which the lateral spread of radiation damage was shown directly by transmission electron microscopy (TEM) on cross-sectional specimens were performed on processed Si wafers implanted with nitrogen [4].

The objective of the present work is to image the damage distribution of a dopant of interest in device technology, e.g. boron, and to calculate the radiation damage distribution near mask edges. The boron was implanted with different doses and energies into $\mathrm{Si}$ wafers structured with chemically etched $\mathrm{Si}$ stripes as implantation mask. A detailed comparison between theory and experiment is here possible because exact data on the radiation damage distribution parameters are available [2].

2. Experimental methods. $-\mathrm{SiO}_{2}$ or $\mathrm{Si}$ mask edges were etched on $\mathrm{Si}$ wafers in the form of a groove grating with a grating constant of $10 \mu \mathrm{m}$. Cross-sectional specimens of the ion-implanted wafers were prepared as shown in figure 1 by the method first described by Petitt and Booker [5] and also used to investigate the defect distribution in homogeneously $\mathrm{P}^{+}$implanted and annealed $\mathrm{Si}$ specimens [6].

$2 \times 2 \mathrm{~mm}^{2}$ slabs were cut from the wafers and glued in pairs face to face with epoxy resin (Fig. 1.1), thinned mechanically in the direction of the grooves down to a thickness of less than $100 \mu \mathrm{m}$ (Fig. 1.2), and finally thinned by ion beam etching (Fig. 1.3) until the area of interest for TEM observation (Fig. 1.4) became transparent to the electron beam. Figure 2 shows a TEM micrograph of a specimen area corresponding to figure 1.4. In this particular example the mask edges were triangular oxide stripes and the wafers were implanted with $5 \times 10^{15} \mathrm{~N}^{+}$ ions $/ \mathrm{cm}^{2}$. Figure 3 shows the area around a mask edge in more detail. The dark band of defect clusters is clearly visible.

Since ion bombardement during ion beam etching usually causes a certain amount of specimen heating, the specimen holder was cooled with liquid nitrogen to avoid unintentional annealing.

The TEM investigations were performed with a Siemens ELMISKOP ${ }^{\circledR} 101$ at $100 \mathrm{kV}$ beam voltage. All micrographs are bright field images exhibiting diffraction contrast of defect clusters. 


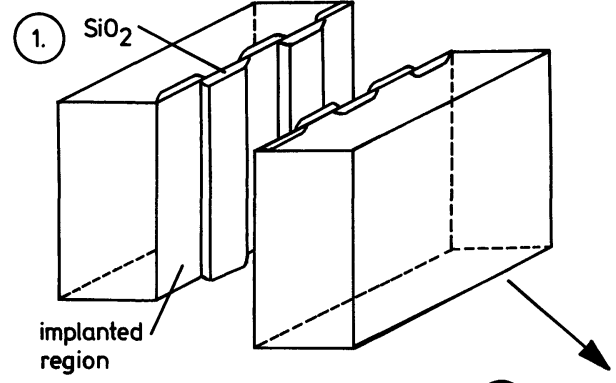

(2.)

(3.)
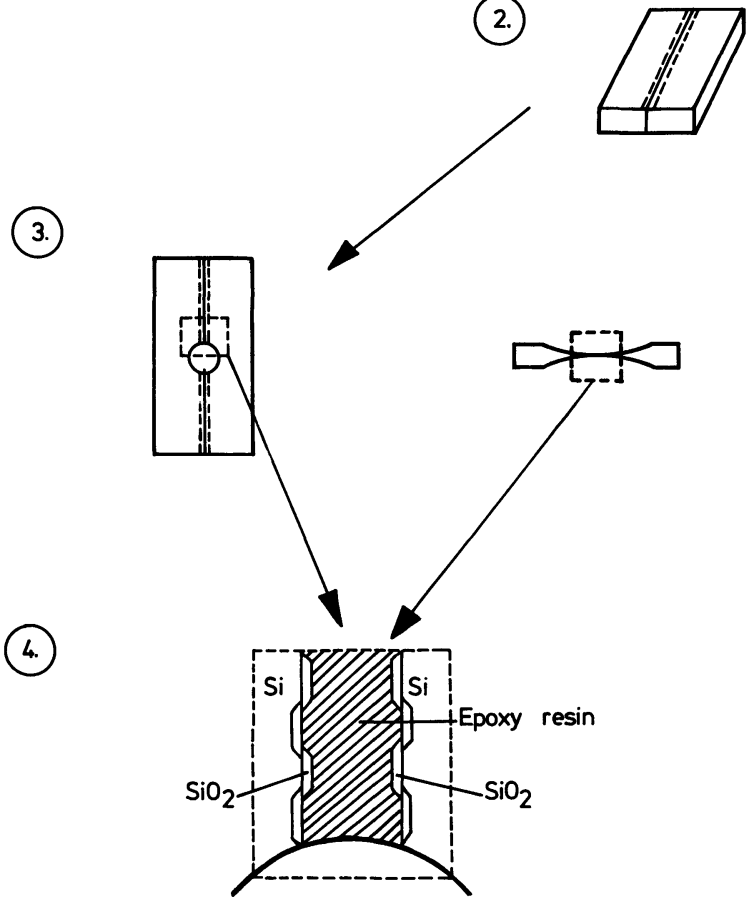

FIG. 1. - Preparation of cross sectional specimens.

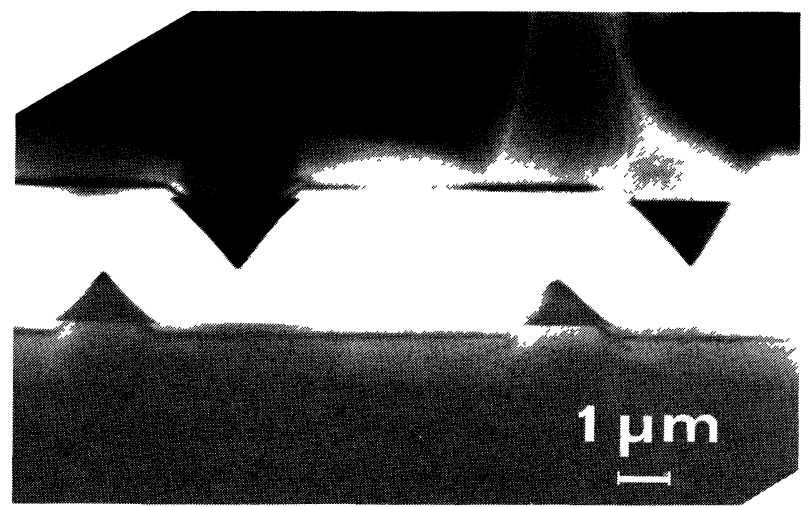

FIG. 2. - TEM micrograph of a cross-sectional specimen showing an area corresponding to figure 1.4. $\mathrm{SiO}_{2}$-stripes on $\mathrm{Si}$ implanted with $5 \times 10^{15} \mathrm{~N}^{+} / \mathrm{cm}^{2}$ at $100 \mathrm{keV}$.

3. Theory. - Figure 4 shows a cross-section through an implanted specimen. The $y$-axis is omitted. Following Matsumura's calculations [2], the damage density due to the implantation of a single ion can be expressed

$$
n_{\mathrm{D}}(x, y, z)=A(z) \exp \left[-\left(x^{2}+y^{2}\right) /\left(2 L_{\mathrm{D}}^{2}(z)\right)\right] \text {. }
$$

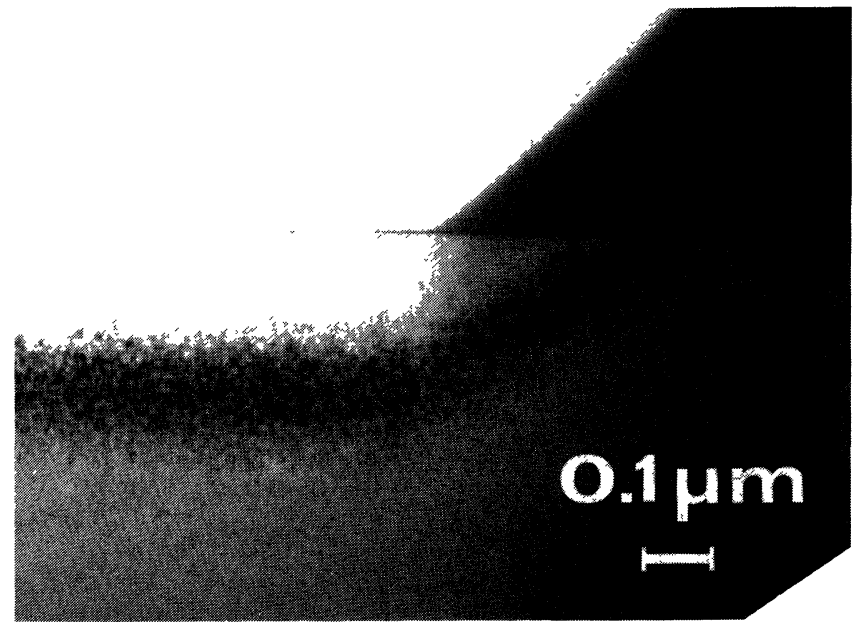

FIG. 3. - Radiation damage (dark band of defect clusters) near mask edge of figure 2 with higher magnification.

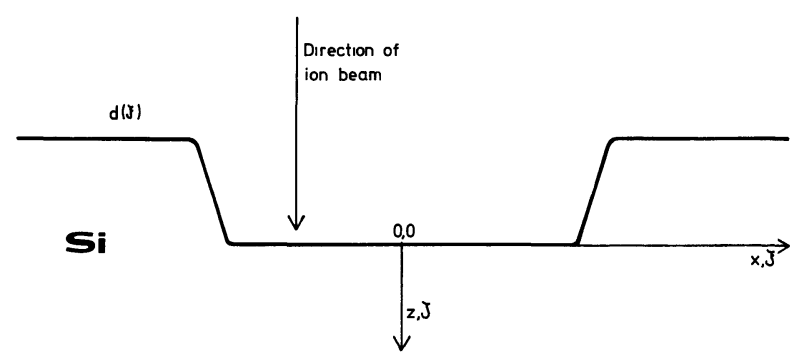

FIG. 4. - Schematic cross section of a sample showing the coordinate system used for the calculations.

$A(z)$ is the damage density along the $z$-axis and $L_{\mathrm{D}}(z)$ the width of the distribution at the depth $z . L_{\mathbf{D}}(z)$ and $A(z)$ depend on the type of implanted ion, the implantation energy and the target material. Using these functions the damage density $F_{\mathrm{D}}$ near mask edges can be determined analogously to the preceding calculations for the lateral spread of implanted ions [3]. This yields

$$
\begin{aligned}
& F_{\mathrm{D}}(x, y, z)=N_{\square} \sqrt{2 \pi} \int_{-\infty}^{\infty} L_{\mathbf{D}}(z-d(\xi)) \times \\
& \quad \times A(z-d(\xi)) \\
& \quad \times \exp \left[-(x-\xi)^{2} /\left(2\left(L_{\mathbf{D}}(z-d(\xi))\right)^{2}\right) \mathrm{d} \xi\right]
\end{aligned}
$$

$d(\xi)$ denotes the outer contour of the specimen and $N_{\square}$ the ion fluence parallel to the surface normal. Using Matsumura's data for $A(z)$ and $L_{\mathrm{D}}(z)$ [2], equation (2) was solved numerically for a $200 \mathrm{keV} \mathrm{B}^{+}$ implant. The two limiting cases of an infinitely high and steep and a round mask edge are shown in figures 5 and 6 . The equidensites in figures 5 and 6 indicate the spatial position in the semiconductor at which the damage density decreases to a factor of $10^{-n}(n=1 \ldots 4)$ of the maximum value. For comparison the mean projected range of the implanted 


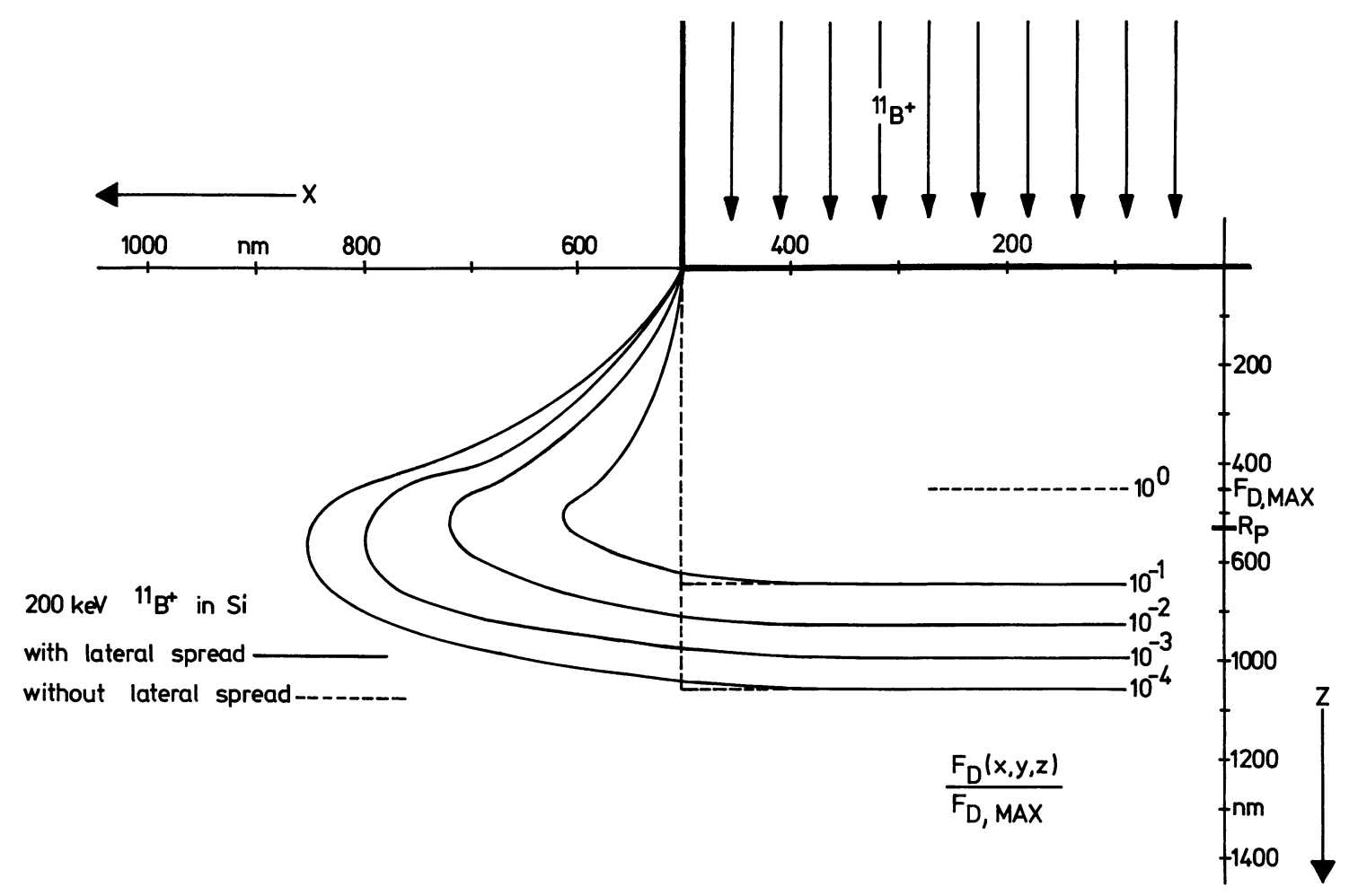

FIG. 5. - Distribution of the normalized radiation damage $F_{\mathrm{D}} / F_{\mathrm{D}, \mathrm{Max}}$ near an infinitely steep and high mask edge.

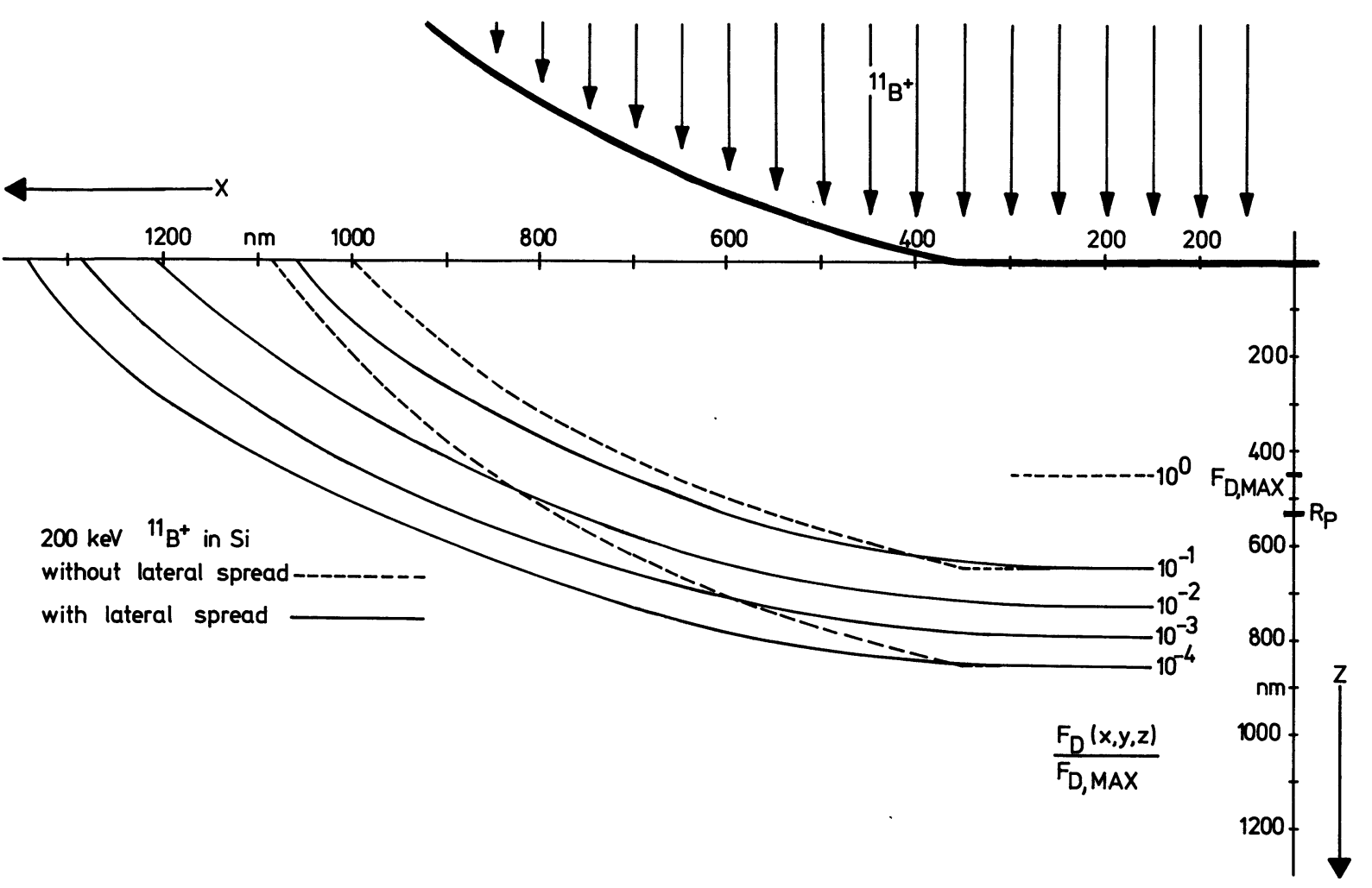

FIG. 6. - Distribution of the normalized radiation damage $F_{\mathrm{D}} / F_{\mathrm{D}, \mathrm{Max}}$ near a chemically etched mask edge (radius of curvature $1.32 \mu \mathrm{m}$ ). 
ions $R_{\mathrm{p}}$ is also given. Figure 5 shows Matsumura's case [1] of an infinitely steep, infinitely high mask edge. The large lateral spread of the radiation damage under the mask edge is obvious. In practical applications an oxide thickness of $d_{0 \mathrm{x}} \geqslant 1 \mu \mathrm{m}$ would represent an infinitely high mask. In device production infinitely steep mask edges cannot however be realized.

Figure 6 shows clearly that lateral spread must not be neglected even in the case of the rather gradual slope of a chemically etched mask with a large radius of curvature. As the stopping power of $\mathrm{SiO}_{2}$ approximately equals that of $\mathrm{Si}$, the calculations and results shown in figures 5 and 6 also apply to $\mathrm{SiO}_{2}$ masks on $\mathrm{Si}$.

In our calculations annealing steps during wafer processing are not included. However, diffusion of defects during anneal will only increase the lateral extension of defects under mask edges, i.e. our results describe the optimum case to be reached in device production.

4. Comparison of theory and experiment. - The effect of lateral spread is the more pronounced the steeper the mask edge. For comparison between theory and experiment very steep mask edges were therefore realized by chemical etching. As it was assumed for the purpose of calculation that the stopping power of the mask and the bulk material were equal, the masks were prepared by etching $\mathrm{Si}$ in the form of a groove grating. The specimens were implanted with $8 \times 10^{15} \mathrm{~B}^{+}$ions $/ \mathrm{cm}^{2}$ at $200 \mathrm{keV}$ and processed as described in section 2 . Figure 7 shows the damage distribution around the mask edge. In the damaged region the defect clusters appear as dark spots due to diffraction contrast with a large deviation from the Bragg condition chosen. The shape of the maximum defect density distribution is obviously not in congruence with the surface contour of the sample, especially in the region of the highest slope of the mask edge. The shape of the mask edge

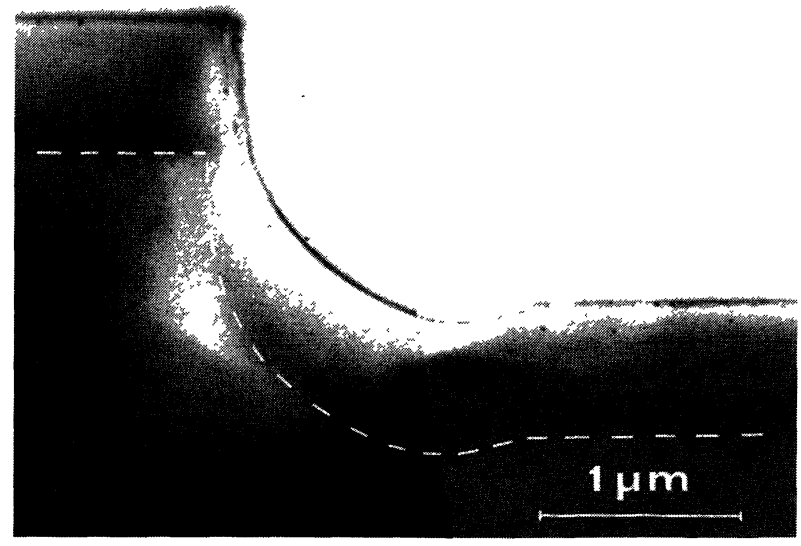

FIG. 7. - TEM micrograph of a cross sectional sample showing the damage distribution near a Si-step on $\mathrm{Si}$ implanted with $8 \times 10^{15} \mathrm{~B}^{+} / \mathrm{cm}^{2}$ at $200 \mathrm{keV}$. The dashed white line indicates the lower boundary of the radiation damage region. $d(\xi)$ was described mathematically by two straight lines and two circular arcs. Using this data, equation (2) was solved on a computer. No adjustable parameters were included in the calculation. The result is shown in figure 8 . The stippled area is the experimentally determined damage region in figure 7 . The lower limit of the damage region corresponds to a depth in the $\mathrm{Si}$ where the damage has decreased to about $10 \%$ of its maximum value.

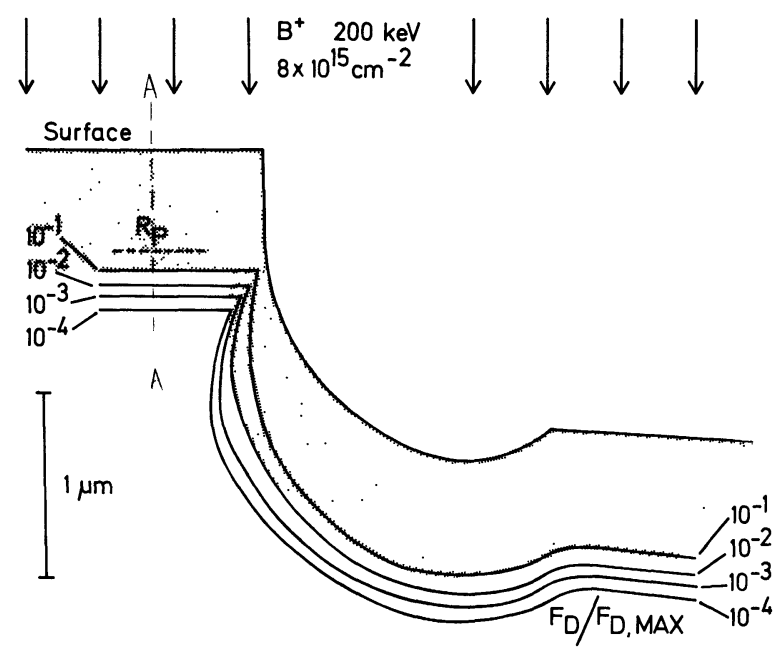

FIG. 8. - Calculated damage distribution $F_{\mathrm{D}} / F_{\mathrm{D}, \mathrm{Max}}$ of the sample geometry shown in figure 7 . The stippled area represents the damage region of figure 7 .

A light modification of the computer program used to solve equation (2) allows the calculation of the depth profile of the damage. In figure 9 the damage distribution is shown in a flat surface region e.g. corresponding to a cross section through figure 8 along line $\mathrm{A}$. It will be noted that in contrast to the well known Gaussian profile of the implanted ions

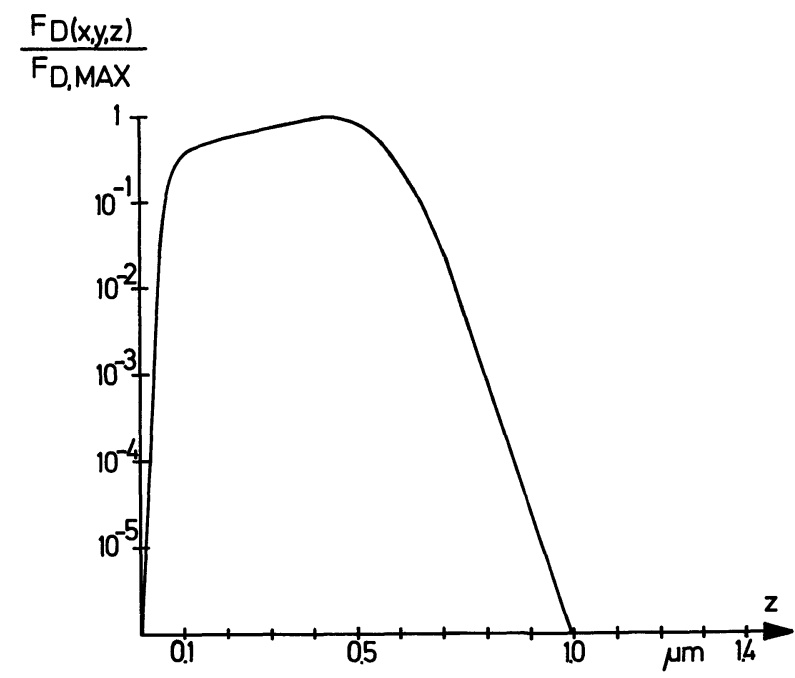

FiG. 9. - Calculated depth distribution of the radiation damage $F_{\mathrm{D}} / F_{\mathrm{D}, \text { Max }}$ in a flat surface region. 


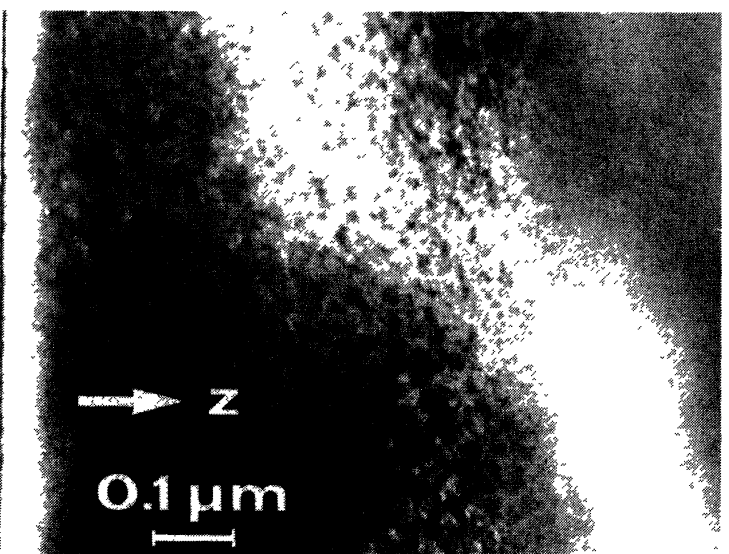

FIG. 10. - Depth distribution of the defect density in a flat surface region (TEM-micrograph).

the damage profile has an almost flat top with a very steep slope at greater depth (log scale !). Figure 10 shows the experimentally determined damage density distribution of a flat surface region. As the specimen was much thinner than the one in figure 7 , the individual defects show up clearly and appear in blackand-white contrast because the specimen is exactly in Bragg orientation. The defects probably consist of small dislocation loops less than $10 \mathrm{~nm}$ in diameter.
As the analysis of the defects is beyond the scope of this work, no detailed analysis (Burger vector, loop plane) was undertaken.

5. Conclusions. - The experiments demonstrate the TEM of cross sectional specimens to be a powerful tool for determining damage distributions in $\mathrm{Si}$ devices.

The excellent agreement between experiment and theory in our investigations shows Furukawa's general model [1] of the damage produced and the damage distribution to yield correct parameters $L_{\mathbf{D}}(z)$ and $A(z)$ which can be used to calculate the three-dimensional damage distribution near arbitrarily shaped mask edges. In real devices the lateral spread of radiation damage and doping concentration after ion implantation is a result of the shape of the mask edge and the spread due to lateral ion scattering. This means that the total lateral spread in production of scaled devices in VLSI technology will reach the same magnitude as the implantation depth $R_{\mathrm{p}}$ and must therefore not be neglected.

Acknowledgments. - The authors thank Ms. G. Eder for preparation of the cross sectional specimens and Ms. H. Fellner for running the computer program.

\section{References}

[1] Matsumura, H., Furukawa, S., Jpn. J. Appl. Phys. 14 (1976) 1983.

[2] Matsumura, H., Furukawa, S., J. Appl. Phys. 47 (1976) 1746.

[3] Runge, H., Phys. Status Solidi (a) 39 (1977) 595.

[4] Krimmel, E. F., Oppolzer, H., Runge, H., VII Intern. Conf. on Atomic Collisions in Solids, 19-23 September 1977,
Moskau, publication pending in the Conference Proceedings.

[5] Petit, H. R., Booker, G. R., Proc. 25th aniv. meeting of EMAG, Inst. Physics (1971) 290.

[6] Sadana, D. K., Fletcher, J. and Booker, G. R., Electron. Lett. 13 (1977) 632. 